\title{
Prevalence of the glaucomas in Nepal
}

Sah R P

\author{
Rana-Ambika Lumbini Eye Institute, Nepal
}

At present: Eritria

Dear Editor,

I read the article titled "Profile of the glaucomas and intervention in a large eye care center in South East Nepal" by Sarkar S et al (2010). The authors deserve special congratulations for presenting such a large hospital database. They have rightly pointed out that the hospital prevalence of primary angle closure glaucoma (PACG) is higher than that of the primary open angle glaucoma (POAG). The reason for this is the sudden-onset nature of the angle closure glaucoma associated with pain and visual impairment. A community survey of glaucoma would have shown the exact picture of the glaucoma prevalence.

The authors state that there is no reported study on the prevalence of glaucoma from South East Nepal (Sarkar S et al 2010). However, according to a community survey by Sah RP et al (2007) in the same region the prevalence of POAG is $0.9 \%$ and the POAG is more prevalent than the PACG. It would be interesting if the barriers in getting the patients with the POAG to the hospital were explored.

The article by Sarkar S et al (2010) has definitely contributed to our understanding of the magnitude and severity of glaucoma blindness in the region.

\section{References}

Sah R P et al (2007). Prevalence of glaucoma in Sunsari District of Nepal. Kath Univ Med J; 5:343-8.

Sarkar S et al (2010). Profile of the glaucomas and intervention in a large eye care center in South East Nepal. Nep J Oph; 2 (3): 1-8.

\section{Source of support: nil. Conflict of interest: none}

